\title{
In Support of a Physics-Based Energy Transition Planning: Sowing Our Future Energy Needs
}

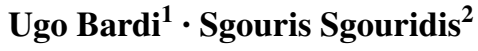

Received: 23 August 2017 / Accepted: 28 October 2017 / Published online: 7 November 2017

(C) Springer International Publishing AG, part of Springer Nature 2017

\begin{abstract}
Attaining the objectives set by the COP21 Paris agreement on climate involves not only phasing out fossil fuels from the world's energy mix but also replacing the energy services they provide with renewable energy and better efficiency, approximately by the mid-twenty-first century. A recent controversy on the viability of $100 \%$ renewable energy systems (Jacobson et al. in Proc Natl Acad Sci 112:15060-15065; Clack et al. in PNAS 114:6722-6727) brought forward the question of whether we can actually rely on renewable energy to replace conventional fossil resources. Focusing on the physical factors involved may offer us a currently underutilized method to reduce controversy showing that, in practical terms, the two parties are closer than immediately apparent. A physical perspective suggests that accelerated deployment of renewable energy sources makes attaining the Paris objectives feasible, although not without a major effort. A policy directed to increase capital investments in an early and fast expansion of the renewable energy and storage infrastructure is a crucial requirement for this purpose.
\end{abstract}

Keywords Renewable energy · Energy transition · EROI · EPBT $\cdot$ Energy efficiency

Ugo Bardi

ugo.bardi@unifi.it

Sgouris Sgouridis

ssgouridis@masdar.ac.ae

1 Dipartimento di Chimica, Università di Firenze, Polo Scientifico di Sesto Fiorentino, 50019 Florence, Italy

2 Engineering Systems and Management, Masdar Institute, Khalifa University, Abu Dhabi, United Arab Emirates

\section{Main Text}

As fighting climate change becomes more and more urgent and important, the question of planning for an energy transition away from fossil fuels becomes critical. A recent controversy on the ability to reach $100 \%$ renewable and reliable energy supply for the US by the 2050s which involved a study by Jacobson et al. (2015) and a rebuttal by Clack et al. (2017) provides an instructive case in point on the difficulty of assessing the feasibility of the transition. Jacobson's team examined the feasibility issue using mostly physical assumptions to answer how such a future energy system might operate. But the main (and the most controversial) point of their paper was the estimate of the costs involved in the transition, something that led them to assert that the transition would not be stupendously expensive to achieve- on the contrary, it would be rather affordable and perhaps even cheaper than business-as-usual. This assertion and the fact that Jacobson implied relevance to the entire global energy system seem to have acted as the primary motivation for Clack et al. to initiate their critique which then focused on specific assumptions and methodological interpretations.

Clack et al. argue that the $100 \%$ goal as described by Jacobson presents unrealistic requirements. That leads them to support a more conservative alternative approach involving nuclear energy but also a slower phase-out of fossil fuels through carbon capture and sequestration (CCS) and, eventually, negative emission technologies (NET) and greater reliance on biomass. However, these are also untested technologies that constitute a precarious global gamble (Fuss et al. 2014) that would similarly fail more than one of the criteria used by Clack et al. to structure their criticism. These were that "the required technologies have been commercially proven at scale at a cost comparable with alternatives; that the technologies 
can, at scale, provide adequate and reliable energy; that the deployment rate required of such technologies and their associated infrastructure is plausible and commensurate with other historical examples in the energy sector; and that the deployment and operation of the technologies do not violate environmental regulations." Making a veritable energy transition literally involves providing our energy in ways that were never employed at such scale before. As a result, requiring historical precedence is unrealistic. This underlines the importance of physical modeling: we do need to create models that do not try to be predictive but explicitly exploratory (Trutnevyte 2016). Ideally, models should respect energy resource limitations, carefully articulate demand projections by the physical capital evolution by sector rather than trend extrapolations, and account for temporal variations, be it hourly or seasonal. By doing so, they can demonstrate the robustness of the proposed configuration and instill trust in the envisioned energy system. Such an effort is not trivial and rather iterative but it should correct issues like the overestimation of biomass potential for energy (Engström et al. 2017), the underutilization of solar PV (Creutzig et al. 2017), and an implicit tendency to propagate known energy system configurations (Kaya et al. 2017).

Pragmatically, there is little doubt that renewable energy resources, mainly solar and wind, can generate flows of high-quality energy comparable, and even superior, to those provided today by fossil fuels (Jacobson and Delucchi 2011; Elliston et al. 2014; Connolly et al. 2016). Studies that consider hourly variability for both demand and supply find that these energy flows can be sufficient not only in aggregate but also when accounting for the time variability of demand with the inclusion of reasonable amounts of storage (Bogdanov and Breyer 2016; Breyer et al. 2017; Ueckerdt et al. 2017). Clearly, to become a perfect substitute for our current energy system, they need to be coupled with technologies for electricity storage, conversion, transportation, and distribution, and new market paradigms for their deployment and adoption. Potentially, it would reverse energy markets from a supply-based bidding system to a demand-based system when the more critical operations are given priority when energy is expensive but where still no demand is unmet. Interestingly, Clack co-authored an earlier paper finding that by 2030 , with the "anticipated costs for wind and solar, carbon dioxide emissions from the US electricity sector can be reduced by up to $80 \%$ relative to 1990 levels, without an increase in the levelized cost of electricity" (MacDonald et al. 2016) using only natural gas as a back-up. Since neither Jacobson nor Clack in their papers considered electrochemical or power-to-liquids storage systems, we would argue that they were still truncating some vital options that have been showing remarkable techno-economic progress (Nykvist and Nilsson 2015).
In any case, the crucial point in this discussion is not to determine the economically optimal path, since we can neither accurately quantify the risks for humankind involved with climate change (Weitzman 2009), nor estimate the trajectory and innovation co-benefits of a concerted technopolitical effort (Porter and Linde 1995) as evidenced by the consistently underestimated reduction in photovoltaic and offshore wind system costs. The basic point that needs to be discussed is the ability of the world's economic system to allocate the necessary resources for the transition in the desired time frame, approximately within the first half of the twenty-first century (Benjamin and Sanderson 2017), satisfying at the same the requirements of the Paris treaty and the unavoidable gradual depletion of the fossil fuels which currently power the world's industrial and agricultural systems.

A first assessment of the feasibility of the transition can be obtained on the basis of the monetary costs involved. In a paper published in 2011 (Jacobson and Delucchi 2011), Jacobson's team estimated the capital investment necessary at around US \$100 trillion. So, if the transition were to be completed by 2050 , the cost would correspond to about US $\$ 3$ trillion dollars per year, an order of magnitude higher than the current yearly investments in new renewable energy systems [around \$287.5 billion in 2016 (Ryan 2017)]. In 2015, the global gross domestic product (GDP) was ca. US \$74 trillion; therefore, paying for the transition would require spending about $4 \%$ of the current world GDP every year for some 30 years. In these terms, the task is difficult, but certainly feasible, at least in principle. However, this kind of evaluation is what led to the kind of controversy we are examining here, likely involving misconceptions and suboptimal policy decisions since it does not consider some essential physical requirements for the transition. An important consideration missing in this monetary view is that the GDP is an aggregated measurement of the monetary value of all the goods and services produced by the economy, but not all that the economy produces can be directly transformed into the kind of equipment needed for the transition: energy plants, transmission lines, storage plants, and the industrial capacity to manufacture them at scale. We can identify a common requirement for these factors in terms of the energy investment required to extract minerals, refine them, produce components, assemble them, transport them, and other related physical actions. In the current situation, these energy investments can only come from fossil fuels and we referred to this need in a previous paper (Sgouridis et al. 2016) in terms of "The Sower's Path," that is in terms of the need of using some of our current energy production ("the seed") in order to produce renewable energy (the future "harvest").

On this basis, we reframe the question in terms of the energy investment required for the transition: what fraction of the world's current energy production will be needed for 
it? And can this fraction be small enough so that it will be possible to continue to provide the basic energy services needed by the world's population? These questions can be discussed in terms of the concept of "energy yield" or "energy return" and, in particular, from the "Energy Payback Time" (EPBT), a measurement of the time necessary for a new plant to return an amount of energy equal to the amount invested for its construction. EPBT can be expressed as the ratio of the energy invested in the manufacturing of the plant divided by the yearly energy generated. From this definition, we can derive a measurement of the energy investment necessary in order to obtain a certain yearly production of energy. We perform this calculations in the reasonable assumption of a transition period $\mathrm{T}$ that is less than or equal to the lifetime of the renewable energy installations; in this way, we do not need to take into account plant replacement. For equal intervals of time, the energy invested is $E_{\text {inv }}(t)=E_{\text {target }}($ for $t=T) \times(\mathrm{EPBT} / T)$. If we set " $E_{\text {target }}$ " as the current global production per year and we assume that we want to maintain it constant throughout the transition, then EPBT/T is the ratio of the needed yearly investments to the current yearly production. This is, obviously, an approximation since it does not take into account many factors, including the cost of adapting the energy infrastructure to the kind of energy generated by renewable technologies, mainly electrical power. On the other hand, we need also to consider that technological improvement will reduce energy costs and that the infrastructure includes elements, such as vehicles, transmission lines, and factories, that will need to be replaced anyway over the transition period.

From this perspective, the critical elements that determine the feasibility of the transition are the EPBT of renewable technologies as well as the time required for the transition $(T)$. If, hypothetically, the EPBT were larger than $T$, the transition would be physically impossible since it would require more energy than the amount that could be produced. Instead, for $T=30$ years, EPBT values over ca. 5 years would require investing more than $15 \%$ of the overall energy production every year, hence making the transition extremely difficult, although not completely impossible. Conversely, the values of the EPBT close to or under 1 year would make the transition relatively facile. For instance, an $\mathrm{EPBT}=1$ year implies that about $3 \%$ of the world's energy production would have to be set aside for the transition. Seen in this light, the current values of the EPBT for the most diffuse renewable energy technologies are promising. According to a recent study (Bhandari et al. 2015), the average EPBT for polycrystalline silicon PV plants is in the range of 1.5-4 years, although it can drop below 1 year in good locations and still follows a steep learning curve (Görig and Breyer 2016). The EPBT for wind energy was on average better than for solar (Davidsson et al. 2012), although highquality wind resources are less abundant and more localized than solar resources creating a scale barrier and, being a more mature technology, further wind EPBT reductions would be limited.

These considerations can be compared to the current situation. The nameplate renewable energy capacity that was installed in 2016 was $161 \mathrm{GW}_{\mathrm{p}}$ (IRENA 2017). With an average capacity factor that we can assume to be roughly 0.2 , it corresponds to an average power generation of $32 \mathrm{GW}$. In this case, for renewable technologies with $\mathrm{EPBT}=3$ years, the E_invested is about $100 \mathrm{GW}$, or about $0.8 \%$ of the world's average primary power consumption, 12 TW (IEA 2016). According to these estimates, the current level of energy investments in new renewable energy is not sufficient to attain the transition within the assumed climatic and energetic constraints and should be increased.

These EPBT-based considerations can be confirmed by more detailed calculations that consider the factors such as the mix of different EROIs of renewable energy sources, the gradual depletion of the fossil sources, the increasing human population, the need of storage, and more requirements (Sgouridis et al. 2016). Sgouridis et al. take into account the fact that the current energy system is based on fossil fuels and that, therefore, it will be necessary to invest fossil energy during the initial phases of the transition. The strategy of using fossil fuels to provide their own replacement was termed "the sower's way" taking inspiration from the need of farmers to save some of their current harvest as seed for the following one. Accounting for the initial small base, the model generates results compatible with the simplified calculation presented above. Assuming that the net energy demand stabilizes at $2000 \mathrm{~W} /$ capita and population at 10 billion by 2100 , a possible transition trajectory is shown in Fig. 1. Deployment of new renewable facilities needs to be stepped up rapidly and substantially, reaching $2.5 \mathrm{TW} / \mathrm{y}$ by around 2020 and almost 7.5 TW by 2035 . These initial installation rates are practically independent of the net energy trajectory visualized as cross-sections along the $y$-axis in the contour plot in Fig. 1 due to the need to avoid sharp discontinuities in the net energy availability levels. In other words, SET requires an increase by a factor of 45 in the annual deployed capacity (from $\sim 0.16 \mathrm{TWp} / \mathrm{y}$ in 2016 to $7.5 \mathrm{TWp} / \mathrm{y}$ in 2035). This implies that the growth rate in renewable energy installations should remain above $30 \%$ for at least the next decade before it can be allowed to slow down. Notably, the factor increase in 2035 could be up to 90 if early efforts stall or if we require higher levels of per capita energy by then.

With these calculations, we show that physical factors provide fundamental insight on the challenge that humankind faces: the energy transition will be neither easy nor impossible, but it will require a substantially larger rate of energy investment than the currently allocated one. An increase of the order of magnitude we estimate here 


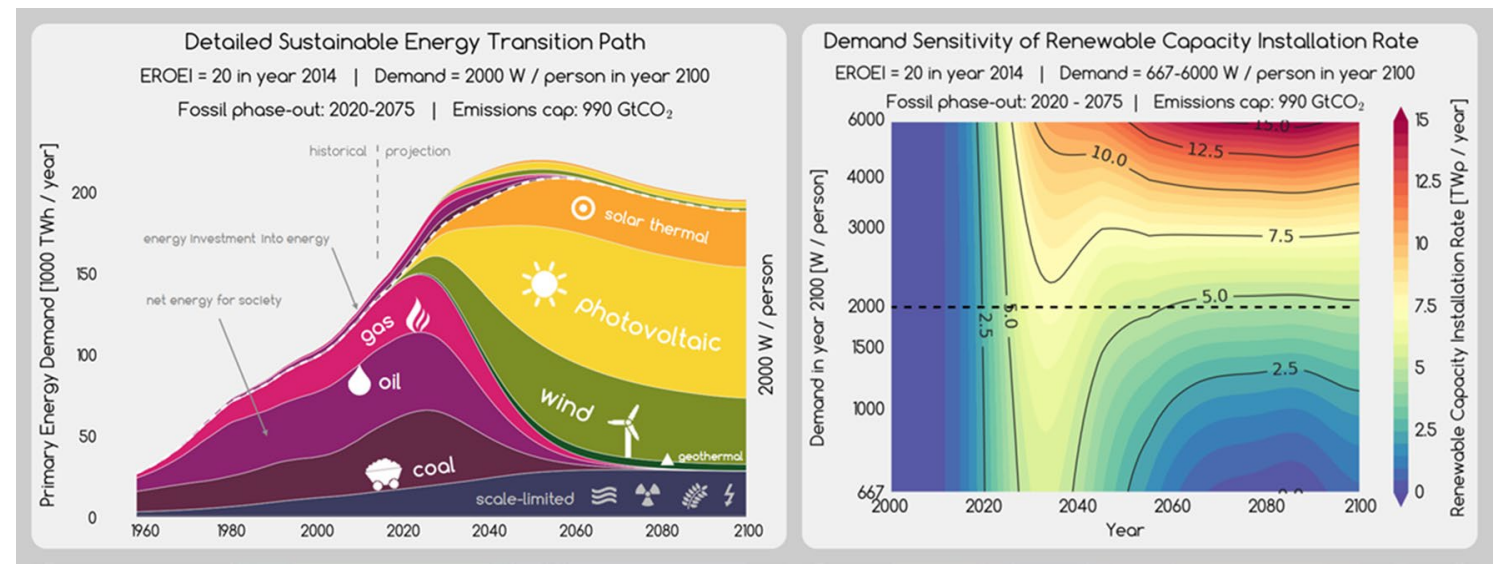

Fig. 1 Detailed physical trajectory for the energy transition when capping emissions at $990 \mathrm{Gt} \mathrm{CO} 2(>\sim 60 \%$ chance of staying within 2C) showing the energy resource distribution for offering net 2000W/ capita (left) and the required installation rate of solar and wind per year for achieving variable levels of net energy demand per capita (right) (image courtesy Denes Csala) will require effort, planning, and resource prioritization. This result contrasts with the optimistic view that market factors alone will be sufficient to carry out the transition without any reduction in the energy supply. It shows, instead, that a crucial policy priority is, at present, to increase investments in renewable energy as fast as possible. One such avenue is to convince institutional investors that renewable energy expansion in diverse global regions with its long-term, tangible, essentially guaranteed physical energy yields should be preferable to bonds that currently yield negative inflation-adjusted returns (e.g., US treasury bonds) and even nominally negative returns for the cases of German bonds. Governments can establish the confidence that the new renewable infrastructure offers a much better use of their monetary capital issuing energy infrastructure bonds of their own.

From an energy balance and resource availability perspective, we can achieve a 100\% renewable energy system. It will require supporting innovations from research and commercial diffusion of energy storage mechanisms. More than that, it will require planning how much energy will be needed in order to achieve it, also taking storage into account. For such planning, we need to democratize the fora of the energy transition discussions while strengthening the public's trust to the scientific process. A $100 \%$ $\mathrm{RE}$ energy system is neither impossible nor uneconomical. The scientific community and the civil society need to work closely together in helping it become a reality before it is too late to avoid the disastrous effects of climate change.

\section{Compliance with Ethical Standards}

Conflict of interest The authors declare no conflict of interest.

\section{References}

Benjamin BCOCT, Sanderson M, What would it take to achieve the Paris temperature targets? Geophys Res Lett 43:7133-7142 (2017)

Bhandari KP, Collier JM, Ellingson RJ, Apul DS (2015) Renewable and sustainable energy reviews. Renew Sustain Energy Rev 47:133-141

Bogdanov D, Breyer C (2016) North-east asian super grid for $100 \%$ renewable energy supply: optimal mix of energy technologies for electricity, gas and heat supply options. Energy Convers Manag 112:176-190

Breyer C et al (2017) On the role of solar photovoltaics in global energy transition scenarios. Prog Photovolt 6:520-545

Clack C et al (2017) Evaluation of a proposal for reliable low-cost grid power with $100 \%$ wind, water, and solar. PNAS 114:6722-6727

Connolly D, Lund H, Mathiesen BV (2016) Smart energy Europe_the technical and economic impact of one potential 100\% renewable energy scenario for the European Union. Renew Sustain Energy Rev 60:1634-1653

Creutzig F et al (2017) The underestimated potential of solar energy to mitigate climate change. Nat Energy 2:17140-17149

Davidsson S, Höök M, Wall G (2012) A review of life cycle assessments on wind energy systems. Int $\mathbf{J}$ Life Cycle Assess 17:729-742

Elliston B, MacGill I, Diesendorf M (2014) Comparing least cost scenarios for $100 \%$ renewable electricity with low emission fossil fuel scenarios in the Australian National Electricity Market. Renew Energy 66:196-204

Engström K, Lindeskog M, Olin S, Hassler J, Smith B (2017) Impacts of climate mitigation strategies in the energy sector on global land use and carbon balance. Earth Syst Dyn 8:773-799

Fuss $\mathrm{S}$ et al (2014) Betting on negative emissions F. Nat Publ Group 4:850-853

Görig M, Breyer C (2016) Energy learning curves of PV systems. Environ Prog Sustain Energy 35:914-923

IEA (2016) Key world energy statistics 2016. International Energy Agency, Paris, pp 1-80

IRENA (2017) Renewable capacity statistics 2017. International Renewable Energy Agency (IRENA), Abu Dhabi, pp 1-60

Jacobson MZ, Delucchi MA (2011) Providing all global energy with wind, water, and solar power, part I: technologies, energy 
resources, quantities and areas of infrastructure, and materials. Energy Policy 39:1154-1169

Jacobson MZ, Delucchi MA, Cameron MA, Frew BA (2015) Low-cost solution to the grid reliability problem with $100 \%$ penetration of intermittent wind, water, and solar for all purposes. Proc Natl Acad Sci 112:15060-15065

Kaya A, Csala D, Sgouridis S (2017) Constant elasticity of substitution functions for energy modeling in general equilibrium integrated assessment models: a critical review and recommendations. Clim Change 43:214-225

MacDonald AE et al (2016) Future cost-competitive electricity systems and their impact on US $\mathrm{CO}_{2}$ emissions. Nat Clim Change 6:526-531

Nykvist B, Nilsson M (2015) Rapidly falling costs of battery packs for electric vehicles. Nat Clim Change 5:329-332

Porter ME, Van der Linde C (1995) Toward a new conception of the environment-competitiveness relationship. J Econ Perspect 9:97-118
Ryan J (2017) Clean energy spending drops most on record as china slows growth, pp 1-3. http://www.bloomberg.com

Sgouridis S, Csala D, Bardi U (2016) The sower's way: quantifying the narrowing net-energy pathways to a global energy transition. Environ Res Lett 11:1-8

Trutnevyte E (2016) Does cost optimization approximate the real-world energy transition? Energy 106:182-193

Ueckerdt F et al (2017) Decarbonizing global power supply under region-specific consideration of challenges and options of integrating variable renewables in the REMIND model. Energy Econ 64:665-684

Weitzman ML (2009) On modeling and interpreting the economics of catastrophic climate change. Rev Econ Statist 91:1-19 